\title{
Hemodialysis Catheter-Associated Bacteremia
}

National Cancer Institute

\section{Source}

National Cancer Institute. Hemodialysis Catheter-Associated Bacteremia. NCI

Thesaurus. Code C114728.

The presence of bacteria in the blood caused by an infected hemodialysis catheter. 